\title{
The Effect of Electromagnetic Field of Mobile Phone on Hand Grip and Shoulder Strengths
}

\author{
Umut Yasa ${ }^{1}$, Mustafa Tozun ${ }^{2 *}$, Bulent Aksoy ${ }^{3}$
}

\author{
${ }^{1}$ Chiropractor, Alsancak, Izmir, TURKEY \\ ${ }^{2}$ Izmir Katip Celebi University Medical Faculty, Department of Public Health, Izmir, TURKEY \\ ${ }^{3}$ Bahcesehir University, Faculty of Health Sciences, Department of Orthopedics and Traumatology, Istanbul, TURKEY \\ *Corresponding Author:mtzn76@gmail.com
}

Citation: Yasa, U., Tozun, M. and Aksoy, B. (2022). The Effect of Electromagnetic Field of Mobile Phone on Hand Grip and Shoulder Strengths. European Journal of Environment and Public Health, 6(1), em0098. https://doi.org/10.21601/ejeph/11501

\section{ARTICLE INFO}

Received: 7 Oct. 2021

Accepted: 24 Oct. 2021

\begin{abstract}
Aim: The aim of this study was to evaluate the relationship between holding a mobile phone in the non-dominant hand and the hand grip, the shoulder abduction and flexion strengths on the dominant hand side.

Materials and Methods: This is an observational study. The study was conducted between November 15, 2019 - November 29, 2019 in 61 adults aged 18-30 years in Izmir, Turkey. Three repeated measurements of hand grip strength, shoulder abduction and shoulder flexion strength in dominant hand / on the shoulder of the dominant hand were compared. Measurements were as follows: In the non-dominant hand when there is no mobile phone (Measurement 1); In the non-dominant hand when there is a switched off mobile phone in (Measurement 2); In the non-dominant hand when there is a mobile phone on in standby mode (Measurement 3). In statistical analysis, student $\mathrm{t}$ test and one way or two-way analysis of variance were used for repeated measurements. A p value of $\leqslant 0.05$ was considered statistically significant.

Results: There was no significant difference between the first, second and third measurement results in terms of mean grip strength (for each one $\mathrm{p}>0.05$ ). However, the mean values of shoulder abduction strength and shoulder flexion strength were lower in the third measurements compared to the first measurements (for each one $\mathrm{p} \leqslant 0.05$ ).

Conclusion: There is evidence that the contact with the mobile phone in the nondominant hand will cause an acute decrease in muscle strength, especially in the shoulder girdle. Further studies in large populations on the subject of this study are recommended.
\end{abstract}

Keywords: mobile phone, electromagnetic field, muscle strength, shoulder strength, hand grip strength

\section{INTRODUCTION}

Electromagnetic Fields; frequency range from $0 \mathrm{~Hz}$ to 300 $\mathrm{GHz}$, covers radio frequency fields with extremely low frequency. The operating frequencies of mobile phones are mostly in the range of $900-1800 \mathrm{MHz}$, which corresponds to radiofrequency energy. Mobile phones need to be constantly connected to a particular network in order to be able to track incoming calls, text messages, service messages, social media and receive emails. For this reason, the communication processor operates actively and continues to transmit, even at a low level, in standby mode. The electromagnetic field emitted by a mobile phone not only during active use, but also in standby mode affects the tissues in the area where it is transported (Abhiman et al., 2016). Various studies have reported that upper extremity and neck musculoskeletal system problems occur depending on the use of mobile phones and length of use (Gustafsson et al., 2017; Kalirathinam et al., 2017; Xie et al., 2017; Yang et al., 2017).

Measurement of hand grip strength is a commonly used parameter for the assessment of general muscle strength, especially in health sciences and sports (Gąsior et al., 2018). In various studies; some sociodemographic features such as age, gender and occupation; anthropometric measurements such as height, weight, body mass index and hand dimensions; Relationships between physical activity level and sports, and some chronic diseases, especially rheumatic diseases, and hand grip strength measurements were investigated (Dedeoglu et al., 2013; Eler \& Eler, 2018; Fallahi and Jadidian, 2011; Gencer et al., 2019; Isin et al., 2018; Massy-Westropp et al., 2011; Melekoglu and Arslan, 2019; Narin et al., 2009; Saygin et al., 2017; Temur et al., 2017; Unveren et al., 2013; Yalcin and Rakicioglu., 2018; Yildirim et al., 2010; Yucel and Aki, 2007).

Hand grip strength is low in women and decreases after the age of 35 (Massy-Westropp et al., 2011; Melekoglu \& Arslan, 
2019; Yalcin \& Rakicioglu., 2018; Yildirim et al., 2010). There is a positive correlation between height, weight, body mass index and hand grip strength. Hand grip strength increases as hand area, hand length, and hand circumference increase (Fallahi \& Jadidian, 2011; Isin et al., 2018; Temur et al., 2017). On the athletes, hand grip strength is used to observe the performance of the upper extremity strength. In studies conducted on athletes from various sports branches, it has been reported that hand grip strength increases with increasing sports activity. In addition, hand grip strength has been shown to increase the chance of hitting in sports such as archery and basketball (Eler \& Eler, 2018; Gencer et al., 2019; Isin et al., 2018; Saygin et al., 2017; Unveren et al., 2013; Yildirim et al., 2010). It has been reported that there is a negative correlation between hand grip strength and disease activity, joint damage, pain, disease duration, functional impairment and disability in patients with rheumatoid arthritis (Dedeoglu et al., 2013).

There is no study in the literature showing that hand grip force is affected by mobile phone use. But for all functions of mobile phones, it is necessary to look at the screen sharply. In this case, a position is taken with the arms in front and neck flexion to display the screen. Shoulder and neck muscles are expected to be adversely affected by this position. Mobile phone addiction has been shown to cause pain in the neck and shoulder muscles (AlAbdulwahab et al, 2017; Berolo et al., 2011). It has been shown that the median nerve undergoes deformation depending on the length of mobile phone use, and as a result, ulnar and radial deviations occur (Woo et al., 2016). Alruzayhi et al. (2018) investigated the relationship between cell phone addiction and upper limb range of motion over 300 Saudi university students. They showed that elbow flexion, shoulder flexion, shoulder extension, shoulder abduction, shoulder adduction, and range of motion were negatively affected by the use of smartphones in both shoulder and shoulder rotation. Abdelhameed and Abdel-aziem (2016) planned a study to demonstrate that the posture that has deteriorated due to excessive mobile phone use can be corrected with a 12-week exercise training and postural correction program. Improvements in hand grip strength, key pinch strength and upper extremity symptoms were detected with the applied exercise program. When the literature was reviewed, there was no study investigating the acute effects of cell phone electromagnetic field on shoulder muscle strength. For these reasons, this study was planned.

The aim of this study was to evaluate the relationship between holding a mobile phone in the non-dominant hand and gripping power of the dominant hand and the shoulder abduction and flexion strengths on the shoulder of the dominant hand.

\section{MATERIALS AND METHODS}

\section{Type of Study}

This is an observational study.

\section{Study Period and Study Area}

The study was conducted between November 15, 2019 November 29, 2019 in Izmir, Turkey. All measurements were made in the study rooms of the researchers.

\section{Criteria for Inclusion}

1) Accepting participation in the study, 2) 18-30 years of age (In order not to affect the results of the study, people who under 18 and people who over 30 ages were not included in the study, because of their low strengts of the muscles), 3) No mental disability, 4) No anatomical defect-deformity-anomaly or neuromotor activity or sensory problems in the upper extremities, 5) No upper-extremity nerve-tendon damage and fractures, 6) No visible massiveness or smallness in upper extremity dimensions (Hand circumference, finger length, forearm length etc.), 7) Not being a professional athlete, 8) No contraindications in the application of the hand grip test or shoulder muscle strength tests: a) No open wounds, b) burned tissue in or near the hand area where the dynamometer will be applied, c) no severe osteoporosis, d) not using vitamin D or vitamin B regularly.

\section{Sampling}

Priori power analysis $G *$ Power 3.1 program was used to determine the sample size. In the article which's title is "Effects of smartphone overuse on hand function, pinch strength, and the median nerve", when the relationship between mobile phone usage time and grip strength in Table 3 is examined, it is seen that there is a positive low level statistically significant relationship $(\mathrm{r}=0.350, \mathrm{p}=0.004)$. When this correlation coefficient $r=0.350$ and type I error 0.05 and type II error 0.20 were taken, it was calculated that it would be appropriate to include a minimum of 61 participants in the study with $80 \%$ power (Inal et al., 2015). The study group was occurred 61 adults aged $18-30$ years.

\section{Questionnaire, Scales, Procedures and Defines}

A questionnaire was prepared by the researchers in accordance with the literature (Abdelhameed \& Abdel-aziem, 2016; AlAbdulwahab et al., 2017; Alruzayhi et al., 2018; Berolo et al., 2011; Dedeoglu et al., 2013; Eler and Eler, 2018; Fallahi and Jadidian, 2011; Gąsior et al., 2018; Gencer et al., 2019; Isin et al., 2018; Massy-Westropp et al., 2011; Melekoglu and Arslan, 2019; Narin et al., 2009; Saygin et al., 2017; Temur et al., 2017; Unveren et al., 2013; Woo et al., 2016; Yalcin and Rakicioglu, 2018; Yildirim et al., 2010; Yucel and Aki, 2007). The questionnaire consists of 14 questions. At the beginning of the questionnaire; Sociodemographic questions on age, gender, marital status, place of residence, education level, have a job, social insurance and family income are included. Exposure to electromagnetic field as a result of work and the frequency of using phone / mobile phone for work were questioned. In the following questions; any chronic disease presence, whether there was any disability, and sports activities were questioned. The dominant hand was learned from the participants.

Following the questionnaire, since it is known that muscle strength is affected by physical activity and sports activities, the International Physical Activity Questionnaire-Short Form was applied to determine the physical activity level. The 
International Physical Activity Questionnaire is a validity and reliability questionnaire form which was conducted by Craig (2003) in 12 countries. Reliability and validity of the questionnaire was made in Turkey (Ozturk, 2005). The short form consists of 7 questions. This scale is based on the calculation of MET (metabolic equivalent) value spent by evaluating the physical activity of at least 10 minutes in terms of frequency, duration (minutes) and severity. Those whose total physical activity value is less than 600 MET-minutes / week are defined as having "Low", those with 600-3000 METminutes / week as "Moderate", and those with more than 3000 MET-minutes / week are defined as having "High" intensity physical activity (Cengiz et al., 2009; Keles and Boduroglu, 2007). The validity and reliability of Short Form in Turkey was realised (Savci et al., 2006).

It was decided to use the Smart Phone Addiction Scale-Short Form (SPAS-SF) for the assessment of smartphone addiction. The scale consisting of 10 items and evaluated with six-point Likert rating measures the risk of smartphone addiction. It was developed by Kwon et al. (2013). The scale has one factor and has no subscales. Validity and reliability of the scale for Turkey was conducted by Noyan et al. (2015). The items of the scale were scored from 1 to 6 . Scale scores ranged from 10 to 60 . The higher the score obtained from the test, the higher the risk for dependence. In this study, as in the Korean sample, 31 cut points for men and 33 cut points for women were decided to exist for smartphone addiction.

Jamar brand (Sammons Preston, Inc., Bollingbrook, IL) hydraulic hand dynamometer was used for hand grip strength measurement. The standard position proposed by the American Hand Therapists Association is; sitting position, shoulder adduction and neutral rotation, elbow $90^{\circ}$ flexion, forearm midrotation and supported, the wrist was made to be neutral (Narin et al., 2009).

Shoulder abductor and flexor strength measurements were performed by MicroFET ${ }^{\circledR}-2$ (Hoggan Scientific, LLC.) Hand dynamometry (MicroFET $\left.{ }^{\circledR}-2\right)$. Isometric muscle strengths were measured with MicroFET ${ }^{\circledR}-2$ from the distal humerus in the sitting position, arm 90 degrees abduction, forearm pronation position and arm 90 degree flexion, forearm in neutral position. MicroFET ${ }^{\circledR}-2$ is an easy-to-use, non-invasive test for muscle strength assessment. And validity and reliability studies were conducted (Bohannon, 2004; Schaubert and Bohannon, 2005).

When taking measurements, material such as jewelry, rings, glasses were removed from the participants.

Hand grip strength, shoulder abduction strength and shoulder flexion strengths were performed respectively.

Frequency values of the mobile phone used in the measurements are in the range of $900-2100 \mathrm{Mhz}$, and the SAR values are $0.439 \mathrm{~W} / \mathrm{kg}$ for the head region and $1.144 \mathrm{~W} / \mathrm{kg}$ for the body.

Three measurements were defined for each:

Measurement 1: In the non-dominant hand when there is no mobile phone;

Measurement 2: In the non-dominant hand when there is a mobile phone in closed position;
Measurement 3: In the non-dominant hand when there is a mobile phone on in standby mode.

All measurements were repeated three times. The arithmetic mean value of the three measurements was used as data. Thus, a total of $27(3 * 9)$ measurements were performed on a participant. The measured values are presented in kilogram-force (kgF) units.

In order to provide interobserver consistency, all measurements were performed by a physiotherapist.

Five minutes of rest time was left between hand grip strength, shoulder flexion and shoulder abduction measurements in order not to decrease the muscle strength due to fatigue during the measurement. One hour was spent for all measurements of a participant, including rest periods.

Height and weight measurements from anthropometric measurements were performed in accordance with the standards. Body Mass Index was calculated. Those with a body mass index of less than $18 \mathrm{~kg} / \mathrm{m}^{2}$ were considered to be weak, $18-24.99 \mathrm{~kg} / \mathrm{m}^{2}$ were normal, 25.0-29.99 kg/m² were overweight and $30 \mathrm{~kg} / \mathrm{m}^{2}$ were considered to be obese (Turkey Nutrition and Health Reseach, 2010; Body mass index).

For the study, the participants were informed about the subject and purpose of the study and their verbal consent was obtained. During the data collection phase, the rules in the Declaration of Helsinki were followed. The ethical permissions were received from the Izmir Katip Celebi University Ethical Committee (Decision date/no: 13.11.2019 / 444).

\section{Funding}

No project support was received for this study.

\section{Statistics}

The normal distribution of the numerical variables was evaluated by the Shapiro Wilk normality test and Q-Q graphs. The homogeneity of the variances was evaluated by Levene test. Frequency values are given in $\mathrm{n}(\%)$. Arithmetic mean $( \pm$ standard deviation) values were used for mean values. Student $t$ test was used for comparison of the two means.

In Measurement 1, Measurement 2, Measurement 3 for hand grip strength, shoulder abduction strength, and shoulder flexion strength, comparisons between measurements were made by one-way and two-way repeated measures analysis from general linear models. In repetitive measurements, twoway analysis of variance model statistics were given together with the effect sizes and statistical power of the main effects and interaction effects (group effect, measure effect and group * measure effect). If there was a difference between two-way analysis of variance, the main effect and interaction effects comparisons were evaluated with Bonferroni corrected multiple comparison test.

Statistical Package for Social Sciences (SPSS) 25.0 was used for statistical analysis. A p value of $<0.05$ was considered statistically significant.

\section{RESULTS}

The mean age of the study group was $23.07 \pm 3.57$ (min: 18 , max: 30 ) years. The numbers of women and men were 44 (72.1) 
and 17 (27.9\%), respectively. The proportion of $18-20$ age group was $37.7 \%$ (n: 23 ).

The mean age of the men $(25.12 \pm 3.82)$ was higher than the women's mean age $(22.27 \pm 3.16)$ (t: 2.729 ; p: 0.011). In addition, $85.2 \%$ (n: 52 ) of the study group were single and there were no divorced or widowed, and 63.9\% (n: 39) of the participants were university graduates. All high school graduates were university students (36.1\%, n: 22).

While all participants were living in urban areas, 20 people (32.8\%) were white-collar. Besides, 38 of the study group were unemployed or students. All of the participants had social security. and $62.3 \%$ (n: 38 ) reported the family income as moderate.

Frequency of "Yes, often" answers to the question "Exposure to electromagnetic fields due to work" was $47.5 \%$ (n: 29). Twenty-six (42.6\%) of the participants reported that they used their phone / mobile phone very often due to their work. Only 3 patients (4.9\%) had chronic disease (one thyroid, one fibromyalgia, one diabetes). No one had any disability.

The frequency of those who reported doing regular sports was $11.5 \%$ (n: 7). According to the results of the International Physical Activity Questionnaire Short Form; $32.8 \%$ of the study group had low level of physical activity.

The mean body mass index of the study group was $22.08 \pm$ 3.15. The mean body mass index was higher in men $(24.40 \pm$ $3.12)$ than in women $(21.17 \pm 2.68)(\mathrm{t}: 3.764 ; \mathbf{p}<\mathbf{0 . 0 1})$.

According to body mass index; Of the study group, 50 (82.0\%) were normal, only 2 (3.3\%) were obese and 2 (3.3\%) were weak. The overweight was 7 (11.5\%). The dominant hand was the right hand in 57 (93.4\%) of the participants.

Ferequency of Smart Cell Phone Addiction was 57.3\% (n: 35). The average score obtained from the Smart Cell Addiction Scale Short Form was $32.91 \pm 8.74$.

Some sociodemographic and the other characteristics of the study group are presented in Table 1.

The mean gripping power of dominant hand results for the three measurements were: Measurement 1: $34.65 \pm 9.06 \mathrm{kgF}$, Measurement 2: $34.45 \pm 9.41 \mathrm{kgF}$ and Measurement 3: $34.81 \pm$ $9.35 \mathrm{kgF}$. According to the results of one-way analysis of variance in repeated measurements, there was no difference between the three measurements in terms of hand grip strength (F: 0.996; p: 0.376).

On the shoulder of the dominant hand, the mean shoulder abduction strength results for three measurements were as follows: Measurement 1: $19.47 \pm 6.17 \mathrm{kgF}$, Measurement 2: $18.74 \pm 6.35 \mathrm{kgF}$ and Measurement 3: $17.29 \pm 5.80 \mathrm{kgF}$. According to the results of one-way analysis of variance in repeated measurements; a significant decrease was found in shoulder abduction strength according to Measurement 3 in Measurement 1 (F: 52.081; p<0.001).

On the shoulder of the dominant hand, the mean shoulder flexion strength results for three measurements were as follows: Measurement 1: $19.71 \pm 6.45 \mathrm{kgF}, 19.06 \pm 6.26 \mathrm{kgF}$ ve $17.40 \pm 5.67 \mathrm{kgF}$. According to the results of one-way analysis of variance in repeated measurements; a significant decrease was found in shoulder flexion strength according to Measurement 3 in Measurement 1 (F: 79.546; p<0.001).
Table 1. Some sociodemographic and the other characteristics of the study group

\begin{tabular}{|c|c|c|}
\hline Characteristics & $\mathbf{N}$ & $\%$ \\
\hline \multicolumn{3}{|l|}{ Age group (years) } \\
\hline $18-20$ & 23 & 37.7 \\
\hline $21-25$ & 22 & 36.1 \\
\hline $26-30$ & 16 & 26.2 \\
\hline \multicolumn{3}{|l|}{ Gender } \\
\hline Men & 17 & 27.9 \\
\hline Women & 44 & 72.1 \\
\hline \multicolumn{3}{|l|}{ Marital status } \\
\hline Single & 52 & 85.2 \\
\hline Married & 9 & 14.8 \\
\hline \multicolumn{3}{|l|}{ Residence area } \\
\hline Urban & 61 & 100.0 \\
\hline \multicolumn{3}{|l|}{ Educational level } \\
\hline Collage (University students) & 22 & 36.1 \\
\hline University & 39 & 63.9 \\
\hline \multicolumn{3}{|l|}{ Job } \\
\hline Blue collar & 3 & 4.9 \\
\hline White-collar & 20 & 32.8 \\
\hline Unemployed or student & 38 & 62.3 \\
\hline \multicolumn{3}{|l|}{ Social insurance } \\
\hline Yes & 61 & 100.0 \\
\hline \multicolumn{3}{|l|}{ Family income status } \\
\hline Bad & 5 & 8.2 \\
\hline Moderate & 38 & 62.3 \\
\hline Good & 18 & 29.5 \\
\hline \multicolumn{3}{|c|}{ Exposure to electromagnetic fields due to work } \\
\hline Yes, often & 29 & 47.5 \\
\hline Yes, in part & 7 & 11.5 \\
\hline No & 25 & 41.0 \\
\hline \multicolumn{3}{|c|}{ Frequency of using phone / mobile phone due to job } \\
\hline Very often & 26 & 42.6 \\
\hline Frequent & 17 & 27.9 \\
\hline Moderate or rare & 18 & 29.5 \\
\hline \multicolumn{3}{|l|}{ Chronicle disease } \\
\hline Yes & 3 & 4.9 \\
\hline \multicolumn{3}{|l|}{ Disability status } \\
\hline No & 61 & 100.0 \\
\hline \multicolumn{3}{|l|}{ Sport activity } \\
\hline Yes, regularly & 7 & 11.5 \\
\hline Yes, irregularly & 27 & 44.3 \\
\hline No & 27 & 44.3 \\
\hline \multicolumn{3}{|l|}{ Physical activity level } \\
\hline Low & 20 & 32.8 \\
\hline Moderate & 32 & 52.5 \\
\hline High & 9 & 14.8 \\
\hline \multicolumn{3}{|c|}{ Obesity Status According to Body Mass Index } \\
\hline Weak & 2 & 3.3 \\
\hline Normal & 50 & 82.0 \\
\hline Ower-weight & 7 & 11.5 \\
\hline Obese & 2 & 3.3 \\
\hline \multicolumn{3}{|l|}{ Dominant hand } \\
\hline Right & 57 & 93.4 \\
\hline Left & 4 & 6.6 \\
\hline \multicolumn{3}{|l|}{ Smart Cell Phone Addiction } \\
\hline Yes & 35 & 57.3 \\
\hline
\end{tabular}

Comparison of the three repeated measurements of gripping power of dominant hand, shoulder abduction and shoulder flexion strength on the shoulder of the dominant hand were presented in Table 2. 
Table 2. Comparison of the three repeated measurements of gripping power of dominant hand, shoulder abduction and shoulder flexion strength on the shoulder of the dominant hand

\begin{tabular}{|c|c|c|}
\hline Strengths $(\mathrm{kgF})$ & Mean \pm Standard Deviation & $\begin{array}{c}\text { Statistical Analysis (One-way Analysis of } \\
\text { Variance in Repeated Measures)F; } p\end{array}$ \\
\hline \multicolumn{3}{|c|}{ Gripping Power of Dominant Hand } \\
\hline Measurement $1^{*}$ & $34.65 \pm 9.06$ & \multirow{3}{*}{ F: 0.996; p: 0.376} \\
\hline Measurement $2 *$ & $34.45 \pm 9.41$ & \\
\hline Measurement $3^{*}$ & $34.81 \pm 9.35$ & \\
\hline \multicolumn{3}{|c|}{ Shoulder Abduction Strength } \\
\hline Measurement $1^{*}$ & $19.47 \pm 6.17^{\mathrm{a}}$ & \multirow{3}{*}{$\mathrm{F}: 52.081 ; \mathrm{p}<0.001$} \\
\hline Measurement $2 *$ & $18.74 \pm 6.35^{\mathrm{a}}$ & \\
\hline Measurement $3 *$ & $17.40 \pm 5.67^{b}$ & \\
\hline
\end{tabular}

${ }_{\mathrm{a}, \mathrm{b}}$ Statistically significant difference according to Post Hoc analysis $(\mathbf{p}<\mathbf{0 . 0 5})$

\begin{tabular}{ccc}
\hline & Shoulder Flexion Strength & \\
\hline${\text { Measurement } 1^{*}}^{*}$ & $\mathbf{1 9 . 7 1} \pm \mathbf{6 . 4 5 ^ { \mathbf { a } }}$ & F: 79.546; $<<0.001$ \\
\hline Measurement 2* & $\mathbf{1 9 . 0 6 \pm 6 . 2 6 ^ { \mathbf { a } }}$ & \\
\hline Measurement 3* & $\mathbf{1 7 . 4 0 \pm 5 . 6 7 ^ { \mathbf { b } }}$ &
\end{tabular}

a,b Statistically significant difference according to Post Hoc analysis (p: 0.039).

* Measurement 1: In the non-dominant hand when there is no mobile phone; Measurement 2: In the non-dominant hand when there is a mobile phone in closed position; Measurement 3: In the non-dominant hand when there is a mobile phone on in standby mode.

The effects of some variables (Age group, Gender, Marital status, Educational level, Job, Family income status, Exposure to electromagnetic fields due to work, Frequency of using phone / mobile phone due to job, Sport activity, Physical activity level, Obesity status, Dominant hand, Smart Cell Phone Addiction), as well as the effect of measurements on shoulder abduction and shoulder flexion strengths, were evaluated by two-way analysis of variance. For Group * Measure Effects values, statsitically significant was found age group and gender both shoulder abduction and flexion strengths (for each one $\mathbf{p}<\mathbf{0 . 0 5}$ ).

The group * measurement effect values in the Marital status and Educational level variables were found to be influenced by the age variable, since singles and university students were younger. Therefore, age and gender were considered as possible confounding factors, in both shoulder abduction and flexion strengths.

Results of two-way analysis of variance in repeated measurements in comparison of mean shoulder abduction/flexion strengths in terms of Measurement $1 /$ Measurement 2 / Measurement 3 and age group/gender were presented in Table 3 and Table 4.

For shoulder abduction force, two-way analysis of variance was performed again by including factors (age group and gender) which were considered as possible confounding factors. According to the results of the multivariate analysis, the measurement effect showed statistically significant $(\mathbf{F}$ : 36.426; p<0.001). However, "measurement * age", "measurement * gender" and "measurement * age * gender" effect values were not statistically significant (for each one $\mathrm{p}>0.05$ ). Accordingly, in the non-dominant hand when there is no mobile phone or there is a mobile phone in closed position or there is a mobile phone on in standby mode, it was concluded that there was no effect of the other variables on the shoulder abduction strength. Besides, measurements' effect was a real effect.

For shoulder flexion strength, two-way analysis of variance was performed again by including factors (age group and gender) which were considered as possible confounding factors. According to the results of the multivariate analysis, the measurement effect showed statistically significant (F: 58.861; p $\mathbf{0 . 0 0 1 ) . ~ H o w e v e r , ~ " m e a s u r e m e n t ~ * ~ g e n d e r " ~ a n d ~}$ "measurement * age * gender" effect values were not statistically significant (for each one $\mathrm{p}>0.05$ ). "Measurement * age" effect was found significant (F: 5.733; p<0.001). Accordingly, in the non-dominant hand when there is no mobile phone or there is a mobile phone in closed position or there is a mobile phone on in standby mode, it was concluded that there was real effect of the measurements. However, the decrease in shoulder flexion strength as the age group decreases can have a confounding effect on the effect of measurements.

\section{DISCUSSION}

Since the beginning of the twenty-first century as it was in the overall mobile phone usage in the world, it has pervaded rapidly in Turkey. Nowadays, the use of mobile phones, even in elementary school children in Turkey has reached a significant frequency (Deveci et al., 2007; Durusoy et al., 2011). Since all of the people participating in our study are adults using mobile phones, they ask them, "Are you exposed to electromagnetic fields due to your job?" and "How often do you use the phone / cell phone for your business?" We asked questions. The answers we received to these two questions were $47.5 \%$ "Yes, often" and $42.6 \%$ "Very often" respectively. These responses can be interpreted as being exposed to electromagnetic fields quite frequently due to the use of mobile phones within half of the working group. It is possible that the whole working group lives in the urban area and is a university graduate or university student in obtaining these results.

It has been reported that physical activity is related to cardiorespiratory status, metabolic health and bone health as well as muscle strength (Alpozgen and Ozdincler, 2016; Bulut, 2013). The rapid urbanization of countries and the sedentary lifestyle offered by urban life cause an increase in the 
Table 3. Results of two-way analysis of variance in repeated measurements in comparison of mean shoulder abduction/flexion strengths in terms of Measurement 1 / Measurement 2 / Measurement 3 and age group

\begin{tabular}{|c|c|c|c|c|c|c|c|c|}
\hline \multirow{3}{*}{$\begin{array}{l}\text { Shoulder Abduction Strength } \\
\text { (kgF) }\end{array}$} & \multicolumn{6}{|c|}{ Age group } & \multirow{2}{*}{\multicolumn{2}{|c|}{ Test Statistics }} \\
\hline & \multicolumn{2}{|c|}{$16-20(n: 23)$} & \multicolumn{2}{|c|}{$21-25$ (n: 22) } & \multicolumn{2}{|c|}{$26-30(16)$} & & \\
\hline & $\overline{\mathrm{x}}$ & ss & $\overline{\mathrm{x}}$ & ss & $\overline{\mathrm{x}}$ & ss & $F$ & $p$ \\
\hline Measurement $1^{* * *}$ & $17.05^{a A}$ & 3.90 & $18.73^{a A}$ & 5.64 & $23.98^{b A}$ & 7.34 & 7.566 & 0.001 \\
\hline Measurement $2 * *$ & $16.07^{a B}$ & 3.91 & $18.26^{a A}$ & 6.26 & $23.23^{b A}$ & 7.17 & 7.376 & 0.001 \\
\hline Measurement $3^{* * *}$ & $15.24^{a C}$ & 4.00 & $16.86^{a b B}$ & 5.49 & $20.84^{b B}$ & 7.01 & 5.093 & 0.009 \\
\hline \multirow[t]{3}{*}{ Test Statistics } & \multicolumn{2}{|c|}{$F=14.005 ; p<0.001$} & \multicolumn{2}{|c|}{$F=17.042 ; p<0.001$} & \multicolumn{2}{|c|}{$F=35.480 ; p<0.001$} & & \\
\hline & \multicolumn{4}{|c|}{ Model Statistics } & & & & \\
\hline & \multicolumn{2}{|l|}{$F$} & \multicolumn{2}{|c|}{$p$} & \multicolumn{2}{|c|}{ Eta Square } & \multicolumn{2}{|c|}{ Observed power } \\
\hline Group effect & \multicolumn{2}{|l|}{6.807} & \multicolumn{2}{|l|}{0.002} & \multicolumn{2}{|c|}{0.190} & \multicolumn{2}{|c|}{0.906} \\
\hline Measure effect & \multicolumn{2}{|l|}{63.873} & \multicolumn{2}{|l|}{$<0.001$} & \multicolumn{2}{|c|}{0.691} & \multicolumn{2}{|c|}{1.000} \\
\hline Group * Measure effect & \multicolumn{2}{|l|}{3.265} & \multicolumn{2}{|c|}{0.014} & \multicolumn{2}{|c|}{0.101} & \multicolumn{2}{|c|}{0.822} \\
\hline \multirow{3}{*}{$\begin{array}{l}\text { Shoulder Flexion Strength } \\
\text { (kgF) }\end{array}$} & \multicolumn{4}{|c|}{ Age group } & \multirow{2}{*}{\multicolumn{2}{|c|}{$26-30(16)$}} & \multirow{2}{*}{\multicolumn{2}{|c|}{ Test Statistics }} \\
\hline & \multicolumn{2}{|c|}{$16-20$ (n: 23) } & \multicolumn{2}{|c|}{ 21-25 (n: 22) } & & & & \\
\hline & $\overline{\mathrm{x}}$ & ss & $\overline{\mathrm{x}}$ & ss & $\overline{\mathrm{x}}$ & ss & $F$ & $p$ \\
\hline Measurement $1 * *$ & $17.36^{a A}$ & 4.32 & $18.75^{a A}$ & 6.43 & $24.42^{b A}$ & 6.90 & 7.314 & 0.001 \\
\hline Measurement $2^{* * *}$ & $16.44^{a B}$ & 4.05 & $18.31^{a A}$ & 6.12 & $23.86^{b A}$ & 6.65 & 8.618 & 0.001 \\
\hline Measurement $3 * *$ & $15.72^{a C}$ & 3.93 & $16.59^{a B}$ & 5.79 & $20.94^{b B}$ & 6.35 & 4.922 & 0.011 \\
\hline Test Statistics & $F=12.038$ & $<0.001$ & $F=29.2$ & 0.001 & $F=59.9$ & 0.001 & & \\
\hline & & & Model S & & & & & \\
\hline & $F$ & & $p$ & & Eta Squ & & Obsel & ower \\
\hline Group effect & 7.013 & & 0.002 & & 0.195 & & & \\
\hline Measure effect & 90.742 & & $<0.001$ & & 0.761 & & & \\
\hline Group * Measure effect & 7.557 & & $<0.001$ & & 0.207 & & & \\
\hline
\end{tabular}

*: Two-Way Analysis of Variance in Repeated Measurements; a.b: It shows a multi-comparison test with Bonferroni correction between groups. A.B.C shows differences within the group.

*** Measurement 1: In the non-dominant hand when there is no mobile phone; Measurement 2: In the non-dominant hand when there is a mobile phone in closed position; Measurement 3: In the non-dominant hand when there is a mobile phone on in standby mode.

Table 4. Results of two-way analysis of variance in repeated measurements in comparison of mean shoulder abduction/flexion strengths in terms of Measurement 1 / Measurement 2 / Measurement 3 and gender

\begin{tabular}{|c|c|c|c|c|c|c|}
\hline \multirow{3}{*}{$\begin{array}{l}\text { Shoulder Abduction Strength } \\
\text { (kgF) }\end{array}$} & \multicolumn{4}{|c|}{ Gender } & \multirow{2}{*}{\multicolumn{2}{|c|}{ Test Statistics }} \\
\hline & \multicolumn{2}{|c|}{ Men (n: 17) } & \multicolumn{2}{|c|}{ Women (n: 44) } & & \\
\hline & $\overline{\mathrm{x}}$ & ss & $\overline{\mathrm{x}}$ & ss & $F$ & $p$ \\
\hline Measurement $1 * *$ & $26.96^{A}$ & 4.40 & $16.58^{A}$ & 3.89 & 81.112 & $<0.001$ \\
\hline Measurement $2 * *$ & $26.74^{A}$ & 4.32 & $15.65^{B}$ & 3.78 & 97.206 & $<0.001$ \\
\hline Measurement $3 * *$ & $24.52^{B}$ & 4.34 & $14.50^{C}$ & 3.38 & 91.624 & $<0.001$ \\
\hline Test Statistics & \multicolumn{2}{|c|}{$F=24.000 ; p<0.001$} & \multicolumn{2}{|c|}{$F=32.531 ; p<0.001$} & & \\
\hline \multicolumn{7}{|c|}{$\begin{array}{l}\text { Model Statistics } \\
\end{array}$} \\
\hline & $F$ & $p$ & \multicolumn{2}{|c|}{ Eta Square } & \multicolumn{2}{|c|}{ Observed power } \\
\hline Group effect & 94.674 & $<0.001$ & \multicolumn{2}{|c|}{0.616} & \multicolumn{2}{|c|}{1.000} \\
\hline Measure effect & 49.094 & $<0.001$ & \multicolumn{2}{|c|}{0.629} & \multicolumn{2}{|c|}{1.000} \\
\hline Group * Measure effect & 3.661 & 0.032 & & & & \\
\hline \multirow{3}{*}{$\begin{array}{l}\text { Shoulder Flexion Strength } \\
\text { (kgF) }\end{array}$} & \multicolumn{4}{|c|}{ Gender } & \multirow{2}{*}{\multicolumn{2}{|c|}{ Test Statistics }} \\
\hline & \multicolumn{2}{|c|}{ Men (n: 17) } & \multicolumn{2}{|c|}{ Women (n: 44) } & & \\
\hline & $\overline{\mathrm{x}}$ & ss & $\overline{\mathrm{x}}$ & ss & $F$ & $p$ \\
\hline Measurement $1 * *$ & $28.12^{A}$ & 4.15 & $16.47^{A}$ & 3.59 & 118.193 & $<0.001$ \\
\hline Measurement $2 * *$ & $27.11^{B}$ & 4.14 & $15.95^{B}$ & 3.58 & 109.214 & $<0.001$ \\
\hline Measurement $3 * *$ & $24.67^{C}$ & 3.94 & $14.60^{C}$ & 3.19 & 107.197 & $<0.001$ \\
\hline Test Statistics & \multicolumn{2}{|c|}{$F=42.566 ; p<0.001$} & \multicolumn{2}{|c|}{$F=32.818 ; p<0.001$} & & \\
\hline \multicolumn{7}{|c|}{ Model İstatistikleri } \\
\hline & $F$ & $p$ & \multicolumn{2}{|c|}{ Eta Square } & \multicolumn{2}{|c|}{ Observed power } \\
\hline Group effect & 117.138 & $<0.001$ & \multicolumn{2}{|c|}{0.665} & \multicolumn{2}{|c|}{1.000} \\
\hline Measure effect & 73.356 & $<0.001$ & \multicolumn{2}{|c|}{0.717} & \multicolumn{2}{|c|}{1.000} \\
\hline Group * Measure effect & 6.343 & 0.003 & \multicolumn{2}{|c|}{0.179} & \multicolumn{2}{|c|}{0.884} \\
\hline
\end{tabular}


frequency of physical inactivity (Bulut, 2013). Unfortunately, sedentary as a developing country, Turkey has taken its place among the countries also affected the lifestyle. Turkey Nutrition and Health Survey 2010, the incidence of people doing sport is $71.9 \%$. This frequency is $76.6 \%$ among women in the 19-30 age group and 69.5\% among men (Turkey Nutrition and Health Reseach, 2010). The frequency of those who report that they are doing sports regularly in our working group of adults living in the urban area is only $11.5 \%$. Those with low levels of physical activity constituted about one third (32.8\%) of the study group. These results compared with our Turkey said to be compatible with the findings of the general.

The frequency of overweight and obese patients in the study group was $14.8 \%$. Turkey Nutrition and Health Survey 2010 based on the frequency of overweight and obese in our country, which is $64.9 \%$ (Turkey Nutrition and Health Reseach, 2010). Turkey Demographic and Health Survey (DHS) -2018 results provides information about the latest situation regarding obesity in women and published in Turkey. According to TDHS-2018, 52\% of women living in households with the highest level of welfare are overweight or obese. $44 \%$ of women with high school or higher education are overweight or obese. The frequency of overweight and obese among women living in urban areas is 58\% (Turkey Demographic and Health Survey (TNSA), 2018). When obesity increases with age, especially after age 40 . If that thought in our group in our study compared the prevalence of overweight and obese adult population in Turkey, data can be considered to be lower.

The prevalence of right-hand dominance is reported to be 90\% worldwide (Adamo and Taufiq, 2011). In our study, the right-hand dominant ones were represented as $93.4 \%$.

Since 2007, the number of fixed line subscribers has decreased from 18.2 million to 11.5 million in our country. The number of mobile phone subscribers increased from 62 million to 73.6 million. In this rise in the use of smart phones, the share of people in the $\mathrm{Y}$ and $\mathrm{Z}$ generation is high. Our working group is also included in the $\mathrm{Y}$ and $\mathrm{Z}$ generations as individuals aged 18-30. According to Kuyucu (2017) Those born between 1977 - 1994 (Generation Y) are highly intellectual and prone to technology. However, those born after 1995 (generation Z) are a generation that has internalized information and communication technology more than generation Y. In connection with the purpose of our study, smart mobile phone addiction was evaluated with the Smart Mobile Phone Addiction Scale Short Form. This scale is scored between 10 and 60 , and the average score of our study group was $32.91 \pm$ 8.74. This result can be interpreted that the study group has a "moderate" dependency. In addition, achieving the result of "Smartphone addiction" in $57.3 \%$ of the study group can be considered as a finding supporting the "moderate" addiction in the study group.

According to the findings presented in Table 2 in our study, no statistically significant difference was found between measurement $1-2-3$ results in terms of gripping powers of dominant hand ( $\mathrm{p}>0.05)$.

Shoulder muscles; trapezius, deltoid, rotator cuff and rhomboids are large muscle groups such as serratus, levator scapula. At the same time, neck and back muscle groups interact with shoulder muscles in terms of the function of the shoulder. In our study, although measurements were made separately for shoulder abduction and flexion muscles, the functional properties of these muscles are physiologically similar. Therefore, consecutive measurement results were expected to be similar in abduction and flexion muscle strength. The analyzes revealed these similar results. Except for age and gender, other variables were not effective on shoulder abduction and flexion muscles. The effect of age and gender is shown in Table 3 and Table 4. However, for two-way analysis of variance in repeated measurements, it was found that age and gender were not a confounding factor on shoulder abduction force when the analysis was repeated by including age and gender in the model. It was observed that the age variable could be confounding only on the effect of measurement 1 , measurement 2 , measurement 3 results on shoulder flexion strength: Measurement * age effect was found significant ( $\mathbf{p}<\mathbf{0 . 0 0 1})$.

\section{These results can be interpreted as follows:}

Being a man according to being a woman; Also, those between the ages of 26-30 have higher muscle strength, depending on the possible muscle development than the lower age groups. However, it was concluded that "contact with the mobile phone, which is open in standby mode", which led to the measurement effect, caused a real decrease in abduction muscle strength measurements. It was concluded that there is a measurement effect in shoulder flexion strength, but this effect may be affected by the age factor.

As a result of the literature search, the results of the studies similar to the analyzes we conducted for the purpose of this study have not been found in sufficient numbers. Therefore, the discussion of our study is presented as an internal discussion. Gill et al. (2006) is on the range of motion. They reported that shoulder motion range norms reported by the American Academy of Orthopedic Surgeons (AAOS) were not affected by age and gender for the 20-49 age group, and the shoulder motion range of 50 years and older decreased. The work of Gill et al (2006). Was based on shoulder range of motion, not on shoulder muscle strength. However, it suggests that there may be a decrease in shoulder muscle strength at the age of 50 and over. Our business group has been selected between the ages of 18-30 to eliminate this effect.

Interpretation of the study's results according to physiopathological mechanisms:

Although the physiopathological mechanisms of the acute effect of the electromagnetic field of the mobile phone on the shoulder muscle forces are not known, it is expected to be revealed by further studies.

However, when looking at the literature, there are few studies on the effects of magnetic field on muscle tone, these studies focus on some theories on the subject. In this context, there are several possible pre- and post-synaptic mechanisms and regions that may be involved in the effects of the electromagnetic field: (i) the problem of spreading action potential along the nerve axon; (ii) insufficient presynaptic release of acetylcholine (ACh); (iii) insufficient depolarization of the postsynaptic membrane, (iv) failure in action potential propagation during sarcolemma, and (v) excitationcontraction linkage problem. The first three factors are the possible main causes of the effects of the magnetic field on 
nerve stimulation on muscle tone, and the last two can explain the effects on muscle stimulation (Satow et al., 2001).

Firstly, if the action potential propagation is blocked or disrupted by exposure of the nerve fibers to the magnetic field, the muscle tone and strength developed in the neuromuscular structure may be reduced. However, previous studies have shown that both the transmission rate is not affected by exposure to magnetic field (Schwartz, 1978, 1979) and the compound muscle action potential is not reduced by this effect (Satow et al., 1990). Therefore, action potential propagation does not constitute an important factor in the magnetic field effects on muscle tone and strength developing through nerve stimulation.

Changing the ACh release from presynaptic terminals can change muscle tone and strength. The electromagnetic field can reduce the release of $\mathrm{ACh}$ from the nerve terminals, which may be due to a worsening change of presynaptic release mechanisms. Various ions or molecules are involved in the release of neurotransmitters from presynaptic terminals; for example Ca, calmodulin, CAM kinase II, synapsin I, ATP and A kinase (Kuno, 1995). The electromagnetic field can affect some of these factors. However, it would be very speculative to discuss more in the current situation.

The sensitivity change of cholinergic receptors in the motor endplate is a possible result of the effects of the magnetic field. A decrease in sensitivity (desensitization) is seen at ACh receptors at the neuromuscular junction (Katz \& Thesleff, 1957). In desensitization induction, phosphorylation of ACh receptors including A kinase, C kinase and tyrosine kinase enzyme activity (Hopfield et al., 1988), cyclic AMP activity (Albuquerque et al., 1986) is required. If the magnetic field affected one of these processes, muscle strength could be affected accordingly.

When the excitability of sarcolemia changes, the development of muscle tone and strength can be affected. Ca is an important factor in muscle contraction (Sweeney et al., 1990). Therefore, when the magnetic field affects the functions of Ca in muscle contraction, it will change the development of muscle tone. Another factor potentially affected by the magnetic field are large molecular enzymes: the calmodulin molecule, myosin light chain, myosin light chain kinase, and the ATP molecule. Markov and Pilla (1994) suggested in their previous studies that the possibility of $\mathrm{Ca}$ binding can be changed by applying a Direct Current (DC) magnetic field. Altenating Current (AC) and DC magnetic fields also affect the phosphorylation of myosin light chain in cell-free preparation (Markov et al., 1993).

In another study, muscle equivalent fluid models were created to determine the possible effects of mobile phones at $900 \mathrm{MHz}$ and $1800 \mathrm{MHz}$ operating frequencies, wireless communication devices at $2.45 \mathrm{GHz}$ operating frequency and medical physiotherapy treatment device (short wave diathermy device) at $27.12 \mathrm{MHz}$ frequency on human muscle tissue. It has been observed that exposure to an electromagnetic field, especially at 900, 1800 and $2450 \mathrm{MHz}$ frequencies, in muscle equivalent fluid models, causes temperature rises in the muscle tissue (Polat and Comlekci, 2019).

\section{Strengths}

No similar study was found in the literature. The results of the study will make an important contribution to the literature. The results of the study focused on the acute effect on the muscle strength of mobile phones. Previous studies have evaluated chronic effects.

\section{Limitations}

1) In this study, 61 people who were sufficient for the sample volume were reached. There may be a limitation to not being able to work in a larger population.

2) Twenty seven measurements were made in one session on one participant. Although sufficient rest periods are given, it may be thought that results may be affected with reason of fatigue.

3) Since many measurements were made on one participant, it was not possible to repeat the measurements in the dominant hand in the nondominant hand.

4) Since measurements are made by a researcher, there is no need to look for consistency between observers. However, intra-observer consistency had to be tested. This study could not be done due to the shortness of the working period.

5) Another limitation is not to use the Isokinetic Test Evaluation Device, which is the reference test instead of the hand dynamometer used for the measurement of shoulder abduction and flexion strengths.

\section{CONCLUSION}

The results of this study showed that; While non-dominant hand-held cell phone contact does not affect the gripping power of the dominant hand, it causes a decrease in shoulder abduction and shoulder flexion strengths. Further studies in large populations are recommended to increase the evidencebased power of the data obtained. In terms of public health, the use of mobile phones should be restricted, especially for children of development age. Lack of mobile phones should be included in public education while doing sports, driving in traffic, and doing work that requires attention.

Author contributions: All co-authors have involved in all stages of this study while preparing the final version. They all agree with the results and conclusions.

Funding: No external funding is received for this article.

Acknowledgements: We would like to thank Dr. Mumin Alper Erdogan (Izmir Katip Çelebi University, Faculty of Medicine, and Department of Physiology) for his contribution on the explanation of physiological mechanisms in the discussion section.

Declaration of interest: The authors declare that they have no competing interests.

Ethics approval and consent to participate: Not applicable.

Availability of data and materials: All data generated or analyzed during this study are available for sharing when appropriate request is directed to corresponding author. 


\section{REFERENCES}

Abdelhameed, A. A. and Abdel-Aziem, A. A. (2016). Exercise training and postural correction improve upper extremity symptoms among touchscreen smartphone users. Hong Kong Physiotherapy Journal, 35, 37-44. https://doi.org/10.1016/j.hkpj.2016.06.001

Abhiman, K. and Gayathri, S. (2016). Optimizing power consumption in smartphones: A comprehensive survey. International Journal of Latest Trends in Engineering and Technology, 7(2), 170-175. https://doi.org/10.21172/ 1.72 .529

Adamo, D. E. and Taufiq, A. (2011). Establishing hand preference: Why does it matter? Hand, 6(3), 295-303. https://doi.org/10.1007/s11552-011-9324-X

AlAbdulwahab, S. S., Kachanathu, S. J. and AlMotairi, M. S. (2017). Smartphone use addiction can cause neck disability. Musculoskeletal Care, 15(1), 10-12. https://doi.org/10.1002/msc.1170

Albuquerque, E. X., Deshpande, S. S., Aracava, Y., Alkondon, M. and Daly, J. W. (1986). A possible involvement of cyclic AMP in the expression of desensitization of the nicotinic acetylcholine receptor: A study with forskolin and its analogs. FEBS letters, 199(1), 113-120. https://doi.org/10.1016/0014-5793(86)81235-2

Alpozgen, A. Z. and Ozdincler, A. R. (2016). Physical activity and preventive effect: Review. HSP, 3(1), 66-72.

Alruzayhi, M. K., Almuhaini, M. S., Alwassel, A. I. and Alateeq, O. M. (2018). The effect of smartphone usage on the upper extremity performance among Saudi youth, KSA. Romanian Journal of Rhinology, 8(29), 47-53. https://doi.org/10.2478/rjr-2018-0006

Berolo, S., Wells, R. P. and Amick III, B. C. (2011). Musculoskeletal symptoms among mobile hand-held device users and their relationship to device use: A preliminary study in a Canadian university population. Applied Ergonomics, 42(2), 371-378. https://doi.org/10.1016/j.apergo.2010.08.010

Body mass index (BMI). (n.d.). Available at: http://www.euro. who.int/en/health-topics/disease-prevention/nutrition/ahealthy-lifestyle/body-mass-index-bmi

Bohannon, R. W. (2004). Adequacy of hand-grip dynamometry for characterizing upper limb strength after stroke. Isokinetics and Exercise Science, 12(4), 263-265. https://doi.org/10.3233/IES-2004-0184

Bulut, S. (2013). Saglikta sosyal bir belirleyici; Fiziksel aktivite [A social determinant of health; Physical activity]. Turkish Bulletin of Hygiene \& Experimental Biology/Türk Hijyen ve Deneysel Biyoloji, 70(4), 2015-2214. https://doi.org/ 10.5505/TurkHijyen.2013.67442

Cengiz, C., Ince, M. L. and Cicek, S. (2009). University students' physical activity levels and physical activity preferences. Gazi BESD, 14(2), 23-32.
Craig, C. L., Marshall, A. L., Sjostrom, M., Bauman, A. E., Booth, M. L., et al. (2003) International physical activity questionnaire: 12 -country reliability and validity. Medicine \& Science in Sports \& Exercise, 35, 1381-1395. https://doi.org/10.1249/01.MSS.0000078924.61453.FB

Dedeoglu, M., Gafuroglu, U., Yılmaz, O. and Bodur, H. (2013). The relationship between hand grip and pinch strengths and disease activity, articular damage, pain, and disability in patients with rheumatoid arthritis. Turkish Journal of Rheumatology, 28(2), 69-77. https://doi.org/10.5606/ tjr.2013.2742

Deveci, S. E., Acik, Y., Gulbayrak, C., Demir, A.F., Karadag, M., Kocdemir, E. (2007) Investigation of Frequency of Mobile Phone, Computer and Television Like Electromagnetic Field-Producing Equipment Use Among Primary School Students. Firat Medical Journal, 12(4), 279-283.

Durusoy, R., Hassoy, H., Karababa, A.O., Ozkurt, A. (2011). Cell phone use and related symptoms of 2150 high school students in Bornova. Electromagnetic Fields and Effects Symposium (pp. 203-207), Istanbul. https://doi.org/10.1289 /isee.2011.01852

Eler, N. and Eler, S. (2018). Raket sporlarında kavrama kuvveti [grip strength in racquet sports]. Gazi Beden Eğitimi ve Spor Bilimleri Dergisi, 23(2), 103-110.

Fallahi, A. A. and Jadidian, A. A. (2011). The effect of hand dimensions, hand shape and some anthropometric characteristics on handgrip strength in male grip athletes and non-athletes. Journal of human kinetics, 29, 151-159. https://doi.org/10.2478/v10078-011-0049-2

Gąsior, J. S., Pawłowski, M., Williams, C. A., Dąbrowski, M. J. and Rameckers, E. A. (2018). Assessment of maximal isometric hand grip strength in school-aged children. Open Medicine, 13(1), 22-28. https://doi.org/10.1515/med-20180004

Gencer, Y.G., Igdir, E.C., Temur, H.B., Sarikaya, M., Seyhan, S. (2019) Does hand grip strength affect shot hit rates? Electronic Turkish Studies, 14(1), 371-380. https://doi.org/10.7827/TurkishStudies.13432

Gill, H., Gustafsson, L., Hawcroft, L. and McKenna, K. (2006). Shoulder joint range of motion in healthy adults aged 20 to 49 years. British Journal of Occupational Therapy, 69(12), 556-561. https://doi.org/10.1177/030802260606901204

Gustafsson, E., Thomée, S., Grimby-Ekman, A. and Hagberg, M. (2017). Texting on mobile phones and musculoskeletal disorders in young adults: a five-year cohort study. Applied Ergonomics, 58, 208-214. https://doi.org/10.1016/ j.apergo.2016.06.012

Hopfield, J. F., Tank, D. W., Greengard, P. and Huganir, R. L. (1988). Functional modulation of the nicotinic acetylcholine receptor by tyrosine phosphorylation. Nature, 336(6200), 677-680. https://doi.org/10.1038/ $336677 \mathrm{a} 0$

Inal, E.E., Demirci, K., Cetinturk, A., Akgonul, M., Savas, S. (2015) Effects of smartphone overuse on hand function, pinch strength, and the median nerve. Muscle \& nerve, 52(2), 183-188. https://doi.org/10.1002/mus.24695 
Isin, A., Ozus, C.B.O., Melekoglu, T. (2018) The RelationshHp of handgrip Strength and Hand Dimensions in Adolescents Aged between 13-14 Years. Sportif Bakis: Spor ve Egitim Bilimleri Dergisi, 5(1), 9-19.

Kalirathinam, D., Manoharlal, M. A., Mei, C., Ling, C. K., Sheng, T. W. Y., Jerome, A., et al. (2017). Association between the usage of Smartphone as the risk factor for the prevalence of upper extremity and neck symptoms among University students: A cross-sectional survey based study. Research Journal of Pharmacy and Technology, 10(4), 11841190. https://doi.org/10.5958/0974-360X.2017.00213.X

Katz, B. and Thesleff, S. (1957). A study of the 'desensitization' produced by acetylcholine at the motor end-plate. The Journal of Physiology, 138(1), 63-80. https://doi.org/10.1113/jphysiol.1957.sp005838

Keles, I. and Boduroglu, Y. (2007). Exercise test in guiding diagnosis and treatment of heart diseases. Clinic Medicine, 3(3), 12-22.

Kuno, M. (1995). The synapse: function plasticity and neurotrophism (pp. 249). New York/Tokyo: Oxford Science Publications.

Kuyucu, M. (2017) Use of smart phone and problematic of smart phone addiction in young people: "Smart phone (colic)" university youth. Global Media Journal TR Edition, 7(14), 328-359.

Kwon, M., Kim, D. J., Cho, H. and Yang, S. (2013). The smartphone addiction scale: Development and validation of a short version for adolescents. PloS One, 8(12), e83558. https://doi.org/10.1371/journal.pone.0083558

Markov, M. S. and Pilla, A. A. (1994). Modulation of cell-free myosin light chain phosphorylation with weak low frequency and static magnetic ${ }^{\circledR}$ elds. In A. L. Frey (Ed.), On the nature of electromagnetic ${ }^{\circledR}$ eld interactions with biological systems (pp. 127-141). Austin, Texas: R.G. Landes Company.

Markov, M. S., Wang, S. and Pilla, A. A. (1993). Effects of weak low frequency sinusoidal and DC magnetic ${ }^{\circledR}$ elds on myosin phosphorylation in a cell-free preparation. Bioelectrochem. Bioenergy, 30, 119-125. https://doi.org/10.1016/0302-4598(93)80069-7

Massy-Westropp, N. M., Gill, T. K., Taylor, A. W., Bohannon, R. W. and Hill, C. L. (2011). Hand grip strength: Age and gender stratified normative data in a population-based study. BMC Research Notes, 4(1), 1-5. https://doi.org/10.1186/1756-0500-4-127

Melekoglu, T. and Arslan, B. (2019). Association between lean mass and handgrip strength in older adults. Spormetre Beden Egitimi ve Spor Bilimleri Dergisi, 17(2), 188-198. https://doi.org/10.33689/spormetre.519627

MicroFET $^{\circledR}-2$ (Hoggan Scientific, LLC.). (n.d.). Available at: https://hogganscientific.com/product/microfet2-muscletester-digital-handheld-dynamometer

Narin, S., Demirbüken, I., Özyürek, S., Elbi, H. and Eser, E. (2009). Relationship of the grip and pinch strength of the dominant hand with anthropometric measurements of forearm. Dokuz Eylül University Faculty of Medicine, 23, 8185.
Noyan, C. O., Darcin, A. E., Nurmedov, S., Yilmaz, O. and Dilbaz, N. (2015). Validity and reliability of the Turkish version of the smartphone addiction scale-short version among university students. Anadolu Psikiyatri Dergisi, 16(S1), 73-82. https://doi.org/10.5455/apd.176101

Ozturk, M. (2005). The validity and reliability of the International Physical Activity Questionnaire and the determination of physical activity levels of students studying at the university [Science Expertise Thesis]. Ankara: Hacettepe University Health Sciences Institute.

Polat, L. N. O. and Comlekci, S. (2019). Elektromanyetik alan maruziyetinin kas dokusunda oluşturduğu etkinin modellenmesi ve analizi [Modeling and analysis of the effect of electromagnetic field exposure on muscle tissue]. Mühendislik Bilimleri Ve Tasarım Dergisi, 7(3), 498-504. https://doi.org/10.21923/jesd.492533

Satow, Y., Matsunami, K. I., Kawashima, T., Satake, H. and Huda, K. (2001). A strong constant magnetic field affects muscle tension development in bullfrog neuromuscular preparations. Bioelectromagnetics: Journal of the Bioelectromagnetics Society, 22(1), 53-59. https://doi.org/10 .1002/1521-186X(200101)22:1<53::AID-BEM6>3.0.CO;2-5

Satow, Y., Satake, H. and Matsunami, K. I. (1990). Effects of long exposure to large static magnetic field on the recovery process of bullfrog sciatic nerve activity. Proceedings of the Japan Academy, Series B, 66(7), 151-155. https://doi.org/10.2183/pjab.66.151

Savci, S., Ozturk, M., Arikan, H., Inal-Ince, D. and Tokgozoglu, L. (2006). Physical activity levels of university students. Archieves of Turkish Cardiology, 34, 166-172.

Saygin, O., Gursoy, R., Tekin, A., Ceylan, H. I. and Babayigit Irez, G. (2017). Comparison of vertical jump, anaerobic power, hand grip strength, $30 \mathrm{~m}$ sprint and aerobic capacity values of 14-15 year old greco-roman style wrestlers according to their weight classes. ATABESBD,19(3), 36-50.

Schaubert, K. L. and Bohannon, R. W. (2005). Reliability and validity of three strength measures obtained from community-dwelling elderly persons. Journal of Strength and Conditioning Research, 19(3), 717-720. https://doi.org/10.1519/00124278-200508000-00038

Schwartz, J. L. (1978). Influence of a constant magnetic field on nervous tissues: I. Nerve conduction velocity studies. IEEE Transactions on Biomedical Engineering, BME-25(5), 467-473. https://doi.org/10.1109/TBME.1978.326353

Schwartz, J. L. (1979). Infuence of a constant magnetic field on nervous tissue. II. Voltage-clamp studies. IEEE Transactions on Biomedical Engineering, 26(4), 238-243. https://doi.org/10.1109/TBME.1979.326508

Sweeney, H. L. and Stull, J. T. (1990). Alteration of cross-bridge kinetics by myosin light chain phosphorylation in rabbit skeletal muscle: implications for regulation of actinmyosin interaction. Proceedings of the National Academy of Sciences, 87(1), 414-418. https://doi.org/10.1073/ pnas.87.1.414 
Temur, H. B. (2017). The examınation of relationship between the lower and upper extremity measurement of anthropometric values, and hand grip strength and skip distance. Journal of Sports and Performance Researches, 8(1), 1-9.

Turkey Demographic and Health Survey (TNSA). (2018). Hacettepe University Institute of Population Studies, Ankara, Turkey. Available at: http://www.hips.hacettepe.edu.tr/ tnsa2018/rapor/TNSA_2018_anarapor.pdf

Turkey Nutrition and Health Research. (2010). Field application handbook. Available at: https://docplayer.biz.tr/2066439Turkiye-beslenme-ve-saglik-arastirmasi-tbsa-2010-sahauygulamasi-el-kitabi.html

Unveren, A., Sarvan Cengiz, S. and Karavelioğlu, M. B. (2013). The effect of regular swimming education on children's some anthropometric parameters and handgrip strength. Journal of Physical Education \& Sports Science, 7(3), 242-47.

Woo, H. C., White, P., Ng, H. K. and Lai, C. W. (2016). Development of kinematic graphs of median nerve during active finger motion: Implications of smartphone use. PloS One, 11(7), e0158455. https://doi.org/10.1371/ journal.pone. 0158455
Xie, Y., Szeto, G. and Dai, J. (2017). Prevalence and risk factors associated with musculoskeletal complaints among users of mobile handheld devices: A systematic review. Applied Ergonomics, 59, 132-142. https://doi.org/10.1016/ j.apergo.2016.08.020

Yalcin, E. and Rakicioglu, N. (2018). The relationship between hand grip power and health in elderly. Journal of Nutrition and Dietetics, 46(1),77-83.

Yang, S. Y., Chen, M. D., Huang, Y. C., Lin, C. Y. and Chang, J. H. (2017). Association between smartphone use and musculoskeletal discomfort in adolescent students. Journal of Community Health, 42(3), 423-430. https://doi.org/10.1007/s10900-016-0271-x

Yildirim, I., Bas, O., Kabadayi, M., Tasmektepligil, M. Y., Ocak, Y. and Karagoz, S. (2010). Examination of the correlation of hand grip strength with upper extremity physical characteristics in the male players of handball super league. Mustafa Kemal University Journal of Physical Education and Sport Sciences, 1(1), 9-15.

Yucel, H. and Aki, E. (2007). Age related grip strength change according to gender: A pilot study. Ufkun Otesi Bilim Dergisi, 1(1), 42-49. 